Article

\title{
A Novel GEMIN4 Variant in a Consanguineous Family Leads to Neurodevelopmental Impairment with Severe Microcephaly, Spastic Quadriplegia, Epilepsy, and Cataracts
}

\author{
Hesham Aldhalaan 1, ${ }^{+}$, Albandary AlBakheet ${ }^{2,+}$, Sarah AlRuways $2,3, \ddagger$, Nouf AlMutairi $2,3, \ddagger$,

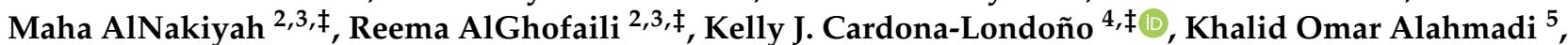 \\ Hanan AlQudairy ${ }^{2}$, Maha M. AlRasheed ${ }^{3}\left(\mathbb{D}\right.$, Dilek Colak ${ }^{6}\left(\mathbb{D}\right.$, Stefan T. Arold ${ }^{4}$ and Namik Kaya ${ }^{2, *(\mathbb{D})}$
}

check for updates

Citation: Aldhalaan, H.; AlBakheet, A.; AlRuways, S.; AlMutairi, N.; AlNakiyah, M.; AlGhofaili, R.; Cardona-Londoño, K.J.; Alahmadi, K.O.; AlQudairy, H.; AlRasheed, M.M.; et al. A Novel GEMIN4 Variant in a Consanguineous Family Leads to Neurodevelopmental Impairment with Severe Microcephaly, Spastic Quadriplegia, Epilepsy, and Cataracts. Genes 2022, 13, 92. https://doi.org/10.3390/ genes13010092

Academic Editor: Allison D. Ebert

Received: 24 October 2021

Accepted: 25 December 2021

Published: 30 December 2021

Publisher's Note: MDPI stays neutral with regard to jurisdictional claims in published maps and institutional affiliations.

Copyright: (C) 2021 by the authors. Licensee MDPI, Basel, Switzerland. This article is an open access article distributed under the terms and conditions of the Creative Commons Attribution (CC BY) license (https:// creativecommons.org/licenses/by/ $4.0 /)$.
1 Neurosciences Department, King Faisal Specialist Hospital and Research Centre, Riyadh 11211, Saudi Arabia; hdhalaan@kfshrc.edu.sa

2 Translational Genomic Department, Center for Genomic Medicine, King Faisal Specialist Hospital and Research Centre, Riyadh 11211, Saudi Arabia; abinbakheet@kfshrc.edu.sa (A.A.); 437200590@student.ksu.edu.sa (S.A.); 437202397@student.ksu.edu.sa (N.A.); 437200678@student.ksu.edu.sa (M.A.); 437202730@student.ksu.edu.sa (R.A.); halqudairy@kfshrc.edu.sa (H.A.)

3 Clinical Pharmacy Department, College of Pharmacy, King Saud University, Riyadh 11211, Saudi Arabia; mahalrasheed@KSU.EDU.SA

4 Division of Biological and Environmental Sciences and Engineering (BESE), Computational Bioscience Research Center (CBRC), King Abdullah University of Science and Technology (KAUST), Thuwal 23955-6900, Saudi Arabia; kelly.cardonalondono@kaust.edu.sa (K.J.C.-L.); stefan.arold@kaust.edu.sa (S.T.A.)

5 Department of Radiology, King Faisal Specialist Hospital and Research Centre, Riyadh 11211, Saudi Arabia; KALAHMADI@kfshrc.edu.sa

6 Department of Biostatistics, Epidemiology and Scientific Computing, King Faisal Specialist Hospital and Research Centre, Riyadh 11211, Saudi Arabia; dkcolak@gmail.com

* Correspondence: nkaya@kfshrc.edu.sa; Tel.: +966-11-4647272 (ext. 39612)

$\dagger \quad$ These authors contributed equally.

$\ddagger$ These authors contributed equally.

\begin{abstract}
Pathogenic variants in GEMIN4 contribute to a hereditary disorder characterized by neurodevelopmental features, microcephaly, cataracts, and renal abnormalities (known as NEDMCR). To date, only two homoallelic variations have been linked to the disease. Moreover, clinical features associated with the variants have not been fully elucidated yet. Here, we identified a novel variant in GEMIN4 (NM_015721:exon2:c.440A>G:p.His147Arg) in two siblings from a consanguineous Saudi family by using whole exome sequencing followed by Sanger sequence verification. We comprehensively investigated the patients' clinical features, including brain imaging and electroencephalogram findings, and compared their phenotypic characteristics with those of previously reported cases. In silico prediction and structural modeling support that the p.His147Arg variant is pathogenic.
\end{abstract}

Keywords: GEMIN4; homoallelic; novel pathogenic variant; in silico prediction; structural modeling; global developmental delay; pediatric cataract

\section{Introduction}

The survival motor neuron (SMN) complex is responsible for the assembly and maturation of the Sm-class of small nuclear ribonucleoproteins (snRNPs), the key components of the spliceosomes [1]. The SMN complex consists of at least nine proteins, one of which is the gem nuclear organelle associated protein 4 (GEMIN4). Immunolocalization experiments showed that GEMIN4 is colocalized with SMN in the cytoplasm and in gems. GEMIN4 has also been detected in the nucleoli, suggesting additional roles in ribosome biogenesis [2].

GEMIN4 and its orthologues are essential molecules for neuromuscular activity and vitality [3] and participate in nuclear receptor binding, microRNA biology [4], and nuclear 
import of the SMN complex [5,6]. Complete gene disruption of Gemin4 in mice results in embryonic lethality [4,5]. Similar findings have been reported for Drosophila melanogaster ortholog Glos [4]. These findings suggest that GEMIN4 and its orthologs play an essential role in the early development of a wide variety of species.

Recently, pathogenic variants in GEMIN4 have been associated with neurodevelopmental features, microcephaly, cataract, and renal abnormalities (named NEDMCR, OMIM Phenotype MIM Number: 617913) [7,8]. Previous publications have briefly reported the clinical features of affected individuals. Here, we provide the detailed clinical presentation and molecular findings in two siblings with NEDMCR.

\section{Materials and Methods}

\subsection{Patients and Ethics}

Two siblings from a consanguineous Saudi family (Figure 1A) were recruited to the project. The patients were extensively examined by board-certified pediatric neurologists at the neuroscience clinics at King Faisal Specialist Hospital and Research Center (KFSHRC). Venous blood samples were collected into EDTA tubes from the probands and available family members after obtaining the signed informed consent (approved by the institutional review board, KFSHRC Research Advisory Council, RAC\#2120022). Blood was further collected from the affected individuals for culturing Epstein-Barr virus-transformed lymphoblastoid cell lines.

A

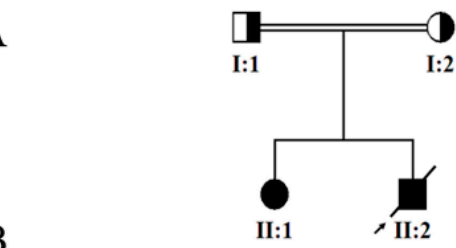

B
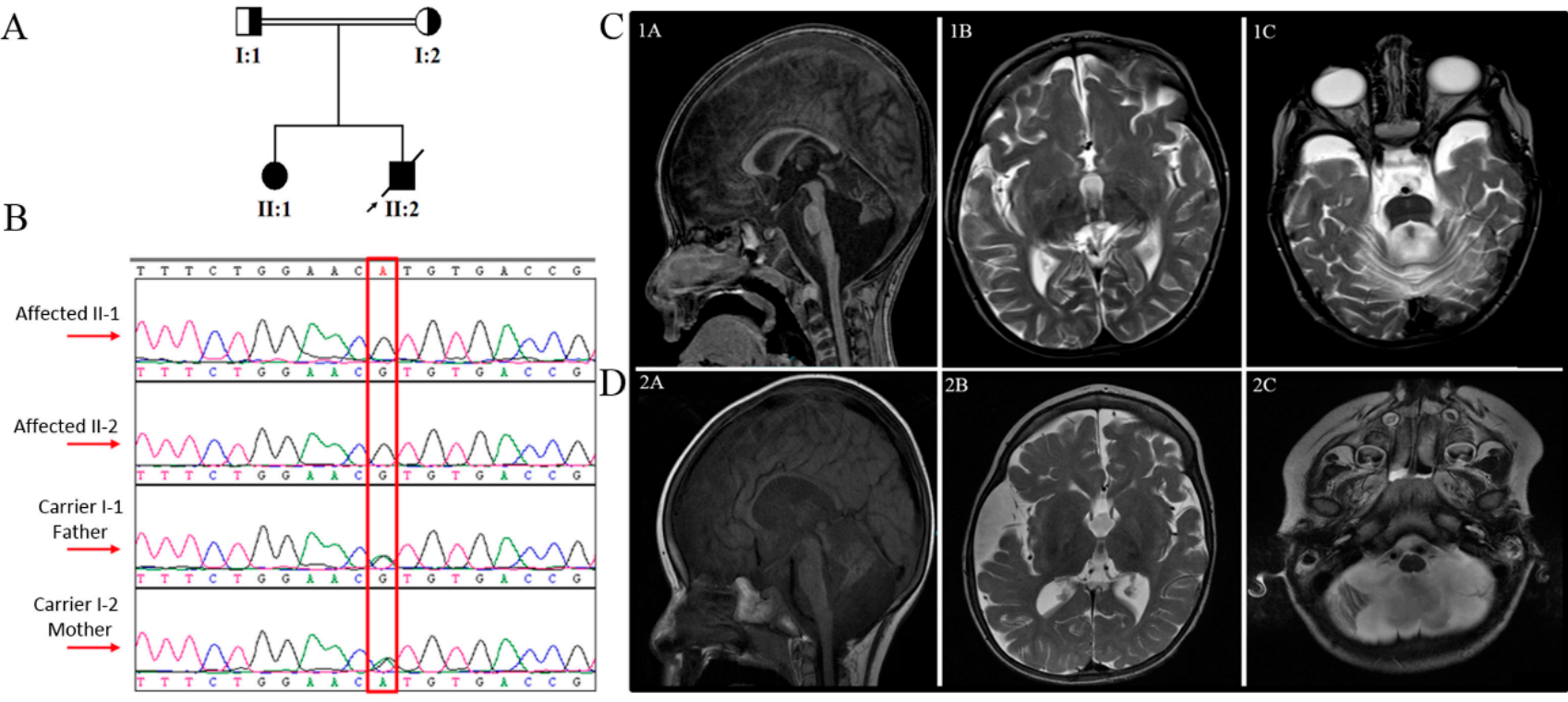

Figure 1. Genetic analysis and brain imaging (MRI) of the patients. (A) The pedigree of the family displays two affected individuals. (B) Sanger sequencing reveals segregation of the variant in the family members. (C,D) Brain MRIs of patients with GEMIN4 novel variant. Sagittal T1WI MRI image (1A) showing significant atrophy of cerebellar hemispheres with the dilation of the fourth ventricle communicating with the retrocerebellar cistern secondary to the significant atrophy of the vermis. The corpus callosum shows significant diffuse atrophy. Sagittal T1WI (2A) sequence indicates the diffuse atrophy of the corpus callosum. There is significant atrophy of the cerebellum with prominent retrocerebellar cistern and volume loss of the brain stem with prominent prepontine cistern. Axial T2WI sequence (1B,2B) shows significant dilatation of the ventricular system with prominent extra-axial CSF spaces extending into lateral sulci. There is an asymmetric dilatation of the ventricular system due to periventricular white matter loss (1C,2C). An incidental prominent basal turn of the cochlea on both sides is observed. 


\subsection{DNA Isolation, $P C R$, Sanger Sequencing}

DNA was extracted from the collected venous blood samples using commercially available kits (Gentra Systems, Minneapolis, MN, USA). The DNA quality and quantity were checked using Nanodrop (ND-1000) or Qubit2.0 Fluorometer (ThermoFisher Scientific Corp., Waltham, MA, USA). Confirmation of the candidate variants obtained from Whole Exome Sequencing (WES) analysis was accomplished using Sanger Sequencing done according to standard protocols.

\subsection{Whole Exome Sequencing (WES) and Variant Detection}

One hundred nanograms of DNA from the index case was utilized as the starting material for the Ion Torrent Proton System. Briefly, DNA was amplified using AmpliSeq kit. The amplicons were then end-repaired and ligated to commercial adapters using DNA ligase. Libraries were barcoded, purified, and the quality assessed according to the manufacturer's recommendations. Ion proton chips and proton system were used to perform the sequencing (ThermoFisher Scientific Corp.).

\subsection{In Silico Pathogenicity Prediction Analyses}

In silico pathogenicity prediction analyses of the identified variants were performed using multiple prediction algorithms, including SIFT [9], Polyphen-2 [10], ClinPred [11], Fathmm [12], Provean [13], MutPred2 [14], MutationAssessor [15], CADD [16], and MutationTaster $[17,18]$.

\subsection{Computational Structural Modeling and Analysis of the Novel Variant}

GEMIN4 sequence was retrieved from the Uniprot [19]. Residue conservation was assessed with Consurf [20]. Psypred [21], Disopred [22], and P-RaptorX [23] were used to predict secondary structure and disorder. PFAM [24], Interpro [25], and Prosite [26] were employed to identify the domain arrangement. The tertiary protein structure was established with AlphaFold2 [27].

\subsection{Tandem Mass Spectrometry}

Sample preparation, metabolite quantification, use of internal standards, and data acquisition and normalization were as described before [28].

\section{Results}

\subsection{Clinical Findings}

Clinical findings of our patients and the previously reported patients, as well as the variants involved in NEDMCR, are presented in Table 1.

Table 1. Clinical and molecular findings of patients in this study, as well as the previously reported variants associated with NEDMCR in the literature.

\begin{tabular}{|c|c|c|c|c|c|c|c|}
\hline & \multicolumn{2}{|c|}{ This Study } & \multirow{2}{*}{$\begin{array}{c}\begin{array}{c}\text { Maddirevula } \\
\text { et al., } 2019 \text { [7] }\end{array} \\
\text { Patient } 3 \\
\end{array}$} & \multirow{2}{*}{$\begin{array}{c}\text { Patel et al., } \\
2017 \text { [8] } \\
\text { Patient } 4\end{array}$} & \multicolumn{3}{|c|}{ Alazami et al., 2015 [29] } \\
\hline & Patient 1 & Patient 2 & & & Patient 5 & Patient 6 & Patient 7 \\
\hline Gender & $\mathrm{F}$ & $\mathrm{M}$ & $\mathrm{F}$ & NA & $\mathrm{F}$ & $\mathrm{M}$ & $\mathrm{F}$ \\
\hline Age of onset & $\begin{array}{c}\text { Few } \\
\text { months }\end{array}$ & 1 month & 7 year & NA & 13 year & 1 year & 5 year \\
\hline Consanguinity & Yes & Yes & Yes & NA & Yes & Yes & Yes \\
\hline $\begin{array}{l}\text { Variant } \\
\text { (cDNA)* }\end{array}$ & c. $440 A>G$ & c. $440 \mathrm{~A}>\mathrm{G}$ & c. $314 \mathrm{C}>\mathrm{T}$ & c. $314 \mathrm{C}>\mathrm{T}$ & c. $2452 \mathrm{~T}>\mathrm{C}$ & c. $2452 \mathrm{~T}>\mathrm{C}$ & c. $2452 \mathrm{~T}>\mathrm{C}$ \\
\hline
\end{tabular}


Table 1. Cont.

\begin{tabular}{|c|c|c|c|c|c|c|c|}
\hline & \multicolumn{2}{|c|}{ This Study } & \multirow{2}{*}{$\begin{array}{c}\begin{array}{c}\text { Maddirevula } \\
\text { et al., } 2019[7]\end{array} \\
\text { Patient } 3\end{array}$} & \multirow{2}{*}{$\begin{array}{c}\begin{array}{c}\text { Patel et al., } \\
2017 \text { [8] }\end{array} \\
\text { Patient } 4\end{array}$} & \multicolumn{3}{|c|}{ Alazami et al., 2015 [29] } \\
\hline & Patient 1 & Patient 2 & & & Patient 5 & Patient 6 & Patient 7 \\
\hline $\begin{array}{c}\text { Variant } \\
\text { (Protein) }\end{array}$ & p.His147Arg & p.His147Arg & p.Pro105Leu & p.Pro105Leu & p.Trp818Arg & p.Trp818Arg & p.Trp818Arg \\
\hline Variant Type & Missense & Missense & Missense & Missense & Missense & Missense & Missense \\
\hline Seizure & Yes & Yes & Yes & Yes & Yes & Yes & Yes \\
\hline GDD & Yes & Yes & Yes & Yes & Yes & Yes & Yes \\
\hline Cataract & Yes & Yes & Yes & Yes & Yes & Yes & Yes \\
\hline $\begin{array}{c}\text { Hearing } \\
\text { impairment }\end{array}$ & Yes & NA & Yes & NA & NA & NA & NA \\
\hline Microcephaly & Yes & Yes & NA & NA & Yes & Yes & Yes \\
\hline Dolichocephaly & NA & Yes & NA & NA & NA & NA & NA \\
\hline Scoliosis & NA & Yes & NA & NA & NA & NA & NA \\
\hline $\begin{array}{l}\text { Dysmorphic } \\
\text { features }\end{array}$ & NA & $\begin{array}{l}\text { High } \\
\text { arched } \\
\text { palate, low } \\
\text { set ears, } \\
\text { wide } \\
\text { depressed } \\
\text { nasal } \\
\text { bridge, } \\
\text { sialorrhea. }\end{array}$ & NA & NA & $\begin{array}{l}\text { Peculiar } \\
\text { orientation } \\
\text { of alae } \\
\text { nasae. }\end{array}$ & $\begin{array}{c}\text { Micrognathia, } \\
\text { small } \\
\text { mandible, } \\
\text { high arched } \\
\text { palate, and } \\
\text { small } \\
\text { bell-shaped } \\
\text { thoracic cage. } \\
\text { HC = 37 cm } \\
(<3 \text { rd centile })\end{array}$ & No \\
\hline $\begin{array}{c}\text { Motor } \\
\text { difficulties }\end{array}$ & Yes & Yes & $\begin{array}{c}\text { Started } \\
\text { walking at the } \\
\text { age of } 2 \text { years }\end{array}$ & NA & Yes & Yes & Yes \\
\hline $\begin{array}{c}\text { Renal } \\
\text { dysfunction }\end{array}$ & NA & $\begin{array}{l}\text { Glycine } \\
\text { elevated }\end{array}$ & NA & NA & Yes & Yes & NA \\
\hline $\begin{array}{c}\text { Chest } \\
\text { infections }\end{array}$ & No & Yes & NA & NA & Yes & Yes & NA \\
\hline MRI & $\begin{array}{c}\text { Medulla, } \\
\text { pons, } \\
\text { cerebellar } \\
\text { vermis, and } \\
\text { both } \\
\text { cerebellar } \\
\text { hemi- } \\
\text { spheres } \\
\text { were rather } \\
\text { small in } \\
\text { size, with } \\
\text { enlarged } \\
\text { cistern } \\
\text { magnum } \\
\text { and the } \\
\text { box-like } \\
\text { appearance } \\
\text { of the } \\
\text { fourth } \\
\text { ventricle. }\end{array}$ & $\begin{array}{l}\text { Generalized } \\
\text { atrophy, } \\
\text { septum } \\
\text { pellucidum } \\
\text { was patent } \\
\text { and } \\
\text { vermian } \\
\text { hypoplasia }\end{array}$ & $\begin{array}{l}\text { Small atrophic } \\
\text { cerebellum } \\
\text { with } \\
\text { prominence of } \\
\text { the posterior } \\
\text { fossa CSF } \\
\text { spaces }\end{array}$ & NA & $\begin{array}{c}\text { Bilateral } \\
\text { symmetri- } \\
\text { cal } \\
\text { alteration } \\
\text { of the } \\
\text { signal } \\
\text { intensity of } \\
\text { the white } \\
\text { matter of } \\
\text { both } \\
\text { cerebral } \\
\text { hemi- } \\
\text { spheres in } \\
\text { the form of } \\
\text { bright } \\
\text { signal } \\
\text { intensity on } \\
\text { T2W and } \\
\text { flair } \\
\text { images, a } \\
\text { picture } \\
\text { probably } \\
\text { reflecting } \\
\text { disturbed } \\
\text { myelina- } \\
\text { tion }\end{array}$ & $\begin{array}{l}\text { Markedly } \\
\text { prominent } \\
\text { cortical sulci } \\
\text { and sub- } \\
\text { arachnoid } \\
\text { cisterns were } \\
\text { noted }\end{array}$ & $\begin{array}{l}\text { Hypomyelination } \\
\text { and callosal } \\
\text { thinning }\end{array}$ \\
\hline
\end{tabular}

Abbreviations: F: Female/M: Male; GDD: Global developmental delay; MRI: Magnetic resonance imaging; NA: Not available. ${ }^{*}$ Variant naming was based on NM_015721. 


\subsubsection{Family A, Patient 1}

The patient is an 11-year-old girl with global developmental delay, infantile spasms, epilepsy, and congenital cataract. She was born to a Saudi consanguineous couple after a full-term normal pregnancy via spontaneous vaginal delivery (SVD). At the age of one month, symptoms began as 10-min clusters of psychomotor epilepsy followed by regression and lack of eye contact. She is currently blind and deaf with a drastically delayed function in less than one year. She continued to experience various types of drug-resistant epilepsy ranging from infantile spasm to symptomatic generalized epilepsy, which improved by the age of eight by using levetiracetam and lamotrigine. She eventually stopped taking both drugs at the age of ten. The surgical correction of a congenital cataract was performed at the age of 5 years, with minimal improvement in visual symptoms. She had severe microcephaly and spastic quadriplegia and was unable to control her head or sit independently. At the age of 4.5 years, the head circumference (HC) was $45.5 \mathrm{~cm}$ (-3 SD, "Standard Deviation"). At the age of 7 years, it was $46 \mathrm{~cm}$ ( $-4.41 \mathrm{SD})$. Initial serum amino acid level study revealed a slight elevation in histidine and valine, methionine, and tyrosine; however, subsequent tests revealed a normal profile. A urine amino acid test was unavailable for the patient. Tandem mass spectrometry (MS) revealed a normal result. The basal cisterns were prominent on MRI (Figure 1C) with atrophy of the medulla, pons, cerebellar tonsils, and both cerebellar hemispheres.

\subsubsection{Family A, Patient 2}

This patient is the younger brother of patient 1. He was born after an uneventful full-term SVD. He suffered from epileptic encephalopathy, infantile spasms, cataracts, and profound global developmental delay. At the age of one month, he developed infantile spasm and up-rolling eyes. He, similar to his sister, continued to have various types of seizures. He suffered from aspiration on a frequent basis, resulting in recurrent pneumonia and the need for nasogastric tube (NGT) feeding. He passed away at the age of nine years secondary to aspiration pneumonia sepsis. On examination, he showed microcephaly, dolichocephaly, and dysmorphic features, with a high arched palate, low set ears, wide depressed nasal bridge, and sialorrhea. His HC was $46 \mathrm{~cm}(-3.25 \mathrm{SD})$ at the age of 4.5 years. He had a cataract in his left eye, hypotonia that progressed to spasticity, as well as brisk plus 3 symmetric reflexes. At the age of two years, he developed scoliosis. The EEGs (electroencephalograms) done at the age of one, two, and three years showed hypsarrhythmia with flexor spasm and clinical seizures. An MRI was performed at the age of three years, displaying an enlargement of the subarachnoid spaces surrounding the frontal, temporal, and posterior fossa structures, suggestive of brain underdevelopment with vermian hypoplasia and persistent cavum interpositum (Figure 1D). His urine analysis showed an elevated glycine value of $2192 \mathrm{mmol} / \mathrm{mol}$ creatinin, whereas serum amino acid analysis was normal. The patient last presented at the age of five, and was well controlled on valproic acid and clobazam. He lasted two years without a seizure.

\subsection{Exome Sequencing and In Silico Functional Prediction Analyses}

We performed WES to identify plausible disease-causing variant(s). Our analysis, coupled with previously published variant filtering processes [30-34], yielded a novel homozygous missense variant in exon 2 of GEMIN4 (NM_015721: c.440A>G:p.His147Arg) as the only candidate underlying the disease. Then we used Sanger sequencing for the segregation analysis and confirmation of the variant in the family. The analysis revealed that the variant was fully segregated with the phenotype. In other words, the affected individuals were homozygous, whereas the parents were carriers (Figure 1A,B). We also searched for the presence of the variant in various databases such as gnomAD, ExAC, dbSNP, and 1000 Genomes, in addition to the Saudi Human Genome Program, including 2379 in-house Saudi exomes. This pursuit did not point out any positive hit assuring the novelty of the variant. To understand the likely deleterious effect of the variant, we utilized various in silico prediction tools and computational structural modeling. 
In silico pathogenicity analyses of the variant using multiple algorithms infered its effect as damaging or disease-causing, including SIFT (damaging, with a score of 0.005), Polyphen-2 (probably damaging, with a score of 0.999), MutationTaster (disease-causing, with score of 1), and others (Supplementary Table S1). We also evaluated the pathogenicity of the previously identified variants causing the disorder. Our evaluation also revealed those as damaging or disease-causing (Suplementary Table S1). The multiple sequence alignment analysis using ClustalW2 for region spanning p. His147Arg indicates the conservation of the mutated residue across species (Figure 2A).

\subsection{Computational Structural Modeling and Analysis of the Novel Variant}

Gemin4 is a 1058 amino acid protein with an estimated molecular mass of $119.9 \mathrm{kD}$ [2]. Its 3-dimensional structure is unknown, and database searches did not reveal any recognizable domain; however, the Ensembl database predicts a short low complexity domain with a PANTHER domain (Figure 2A). Bioinformatic analysis pointed to the existence of three classical (pat7 subtype) nuclear localization sequences (NLS), two in the N-terminal half of the protein (NLS1; residues $\sim 62-69$ aa and NLS2; residues $~ 199-206$ aa) and one located in the C-terminal half (NLS3; residues 714-735). Experimental assays deleting the predicted NLS motifs have demonstrated that NLS2 is necessary and sufficient for the nuclear import of cargoes [4]. The function of the other two putative NLS motifs remains unknown. Computational predictions of tertiary and secondary structure features support the notion of Gemin4 being an elongated all-helical protein, reminiscent of protein structures that serve as scaffolds for assembling protein complexes (Figure 2C). Structural modeling by AlphaFold2 [27] places His147 with a high confidence score (91.44) in a helical region in the vicinity of NLS1 and NLS2. In this model, the highly conserved His147 (conservation score $=0.79$ ) has a key role in tethering several helices together through forming hydrogen and cation-pi bonds with Glu114 and Lys36, respectively, while offering hydrophobic contacts for surrounding polar moieties from Thr110, Phe113, and Phe144. The substitution of His147 with a much larger and charged arginine would either produce serious clashes in the structure or leave an unfavorable hole in this structural region, depending on the arginine rotamer that would prevail (Figure 2C). The resulting structural perturbations could hamper the capability of Gemin4 to bind certain ligands, may affect the accessibility of NLS2, and could lead to an unstable and more rapidly degradable protein. This effect is similar to those evoked by previously reported variants (p.Pro105L and p.Trp818R) that are both destabilizing by introducing clashes and gaps in a hydrophobic environment of the protein fold. P105 is in close proximity to His147, whereas Trp818 is located on the opposite site of the structure (Figure 2D-F). 


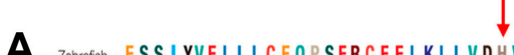
Koala ASGLFIOLLMALPSNICRSELERFVEHVASD TSLEDVTFFLDVWWEMMKHKVD Wombat ASGLFI QLLLALPSNICRSELERFVEHVASD TSLEDVTFFLDVWWEMMKHKVD Eed AAD IFARFLLCLSRSHICTELERLMRHVRSSPTAEDDVQLFLVWWELWKGSND Human ASGLFIQLLMALPTTICHAELERFLEHVTVD TSAEDVAFFLDVWWEVMKHKGH Chimane ASGLFIOLLMLPTTICHAELERELEHVTVD TSSEDVAFFLDVWWEMMKHKGH Bonobo ASGLFIQLLMALPTTICHAELERFLEHVTVD TSSEDVAFFLDVWWEMMKHKGH Morkey ASGLFIQLLMALPTTIRHAELERFLEHVTVD TSSEDVAFFLDVWWEMMKHKGH Mouse ASGLFIQLLMALPTTIGRSELSFLEHMTVD TSSKDVAFFLDVWWEMMKHKGD Eleophant SGLFIQLLMALPTTICRVELERFLEHMTVN TSSKDVAFFLDI WWEMMKHKGN Ther ASGLEIOLLALPTTICBAELEHFLEHMSVD TSSKDVAFFLSVWWEMIKHKGN Cat ASGLFIQLLMALPTTICRAELEHFLEHMSVD TSSKDVAFFLSVWWEMIKHKGN Panda ASGLFIQLLMALPTTICRAELERFLEHMS I D TSSKDVAFFLSVWWEMMKHKGN Fox ASGLFIQLLMALPTTICRAELERFLEHMSVD TSSKDVAFFLSVWWEMMKHKGN Canel SSLFIQLLMALTTICRAELERFLHMTID TSSKDVAFLDVWWEMMKHKGN Rat ASSLFIOLLMALPTTICRTELEHFLEHMTVD TSSKDVAFFLDVWEMMKHKSN She Whale ASGLFI QLLMALPTTVCRAELERFLEHMT I D TSSKDVAFFLDVWWEMMKHKGN Goat ASGLFI QLLMALPTTICRAELERFLEHMTVD TSSKDVAFFLDVWWEMKHKGN

C
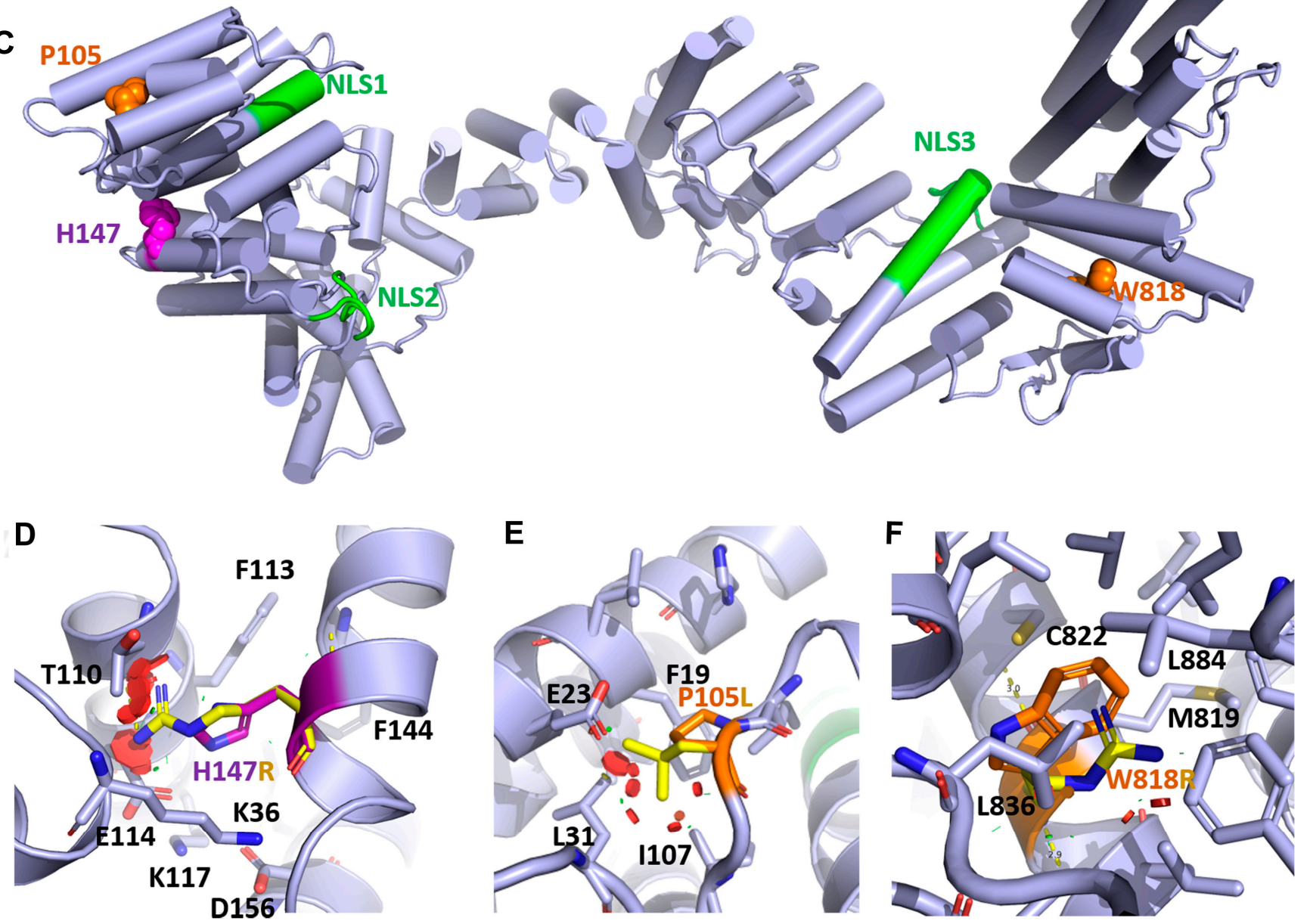

Figure 2. Multiple sequence alignment, schematic drawing of the protein and structural modeling of p.His147Arg. (A) The alignment indicates the conservation of the region surrounding the variant site. (B) All the reported variants are presented on the schematic drawing of the protein. (C) 3D structural models of GEMIN4 predicted with AlphaFold2. Helices are shown as cylinders, and the putative NLS are colored. The residues substituted in the patients described in this report and previous studies are colored in magenta and orange, respectively. (D-F) Zoom into the molecular environment of each variant, with the carbon atoms of the wild-type residues and the variants that are colored in yellow. Clashes introduced by the substitution are represented by red circles, where the orientation and diameter show the direction of clashes, and the disc's thickness illustrates the severity of clashes.

Figures were prepared with PyMOL (pymol.org). 


\section{Discussion}

Homozygous pathogenic variants in GEMIN4 cause the NEDMCR syndrome. Thus far, only two variants, p.Trp818Arg [29] and p.Pro105Leu [7,8], have been reported to cause the disease. This paper highlights a novel homozygous transition (NM_015721:exon2: c.440A > G:p.His147Arg) detected in two siblings born to a consanguineous Saudi family. Clinical examinations revealed similarities and differences between our patients and previously reported individuals. Atypical features such as hearing and speech impairment were found in patient 1 while dolichocephaly, scoliosis, and dysmorphic features were observed in patient 2 who had a high arched palate, low set ears, wide depressed nasal bridge, and sialorrhea. Nonetheless, similarity was seen in the dysmorphic features between patient 2 (c.440A>G:p.H147R) and patient 6 (c.2452T>C:p.W818R) as both had a high arched palate and microcephaly. Recurrent chest infections were noticed in patients 2, 5, and 6, whereas patient 1 exhibited reported NEDMCR syndrome phenotypes. Regarding the renal profile, patient 2 showed an increase in glycine level in urine (tested one time, only). Such increase may be due to valproic acid (VA) since it has been typically associated with hyperglycinuria [35,36]. The MRIs of patients 1 and 2 were almost identical as they showed significant generalized atrophy in the cerebellar hemispheres, corpus callosum, and brain stem. A symmetric dilatation of the ventricular system was also observed due to periventricular white matter loss. However, an enlargement of the subarachnoid spaces was seen in patient 2 , suggestive of brain underdevelopment.

The exact relationship between GEMIN4 pathogenic variants and the syndrome, as well as its potential mediation by SMN complex disruption, are unclear [8]. The observed similarities among the seven patients, collectively presenting three different variants, are consistent (Table 1) [7,8,29]. Previously, three studies have described the effects of this syndrome on patients' neurological functioning $[7,8,29]$. Cataracts were the most common phenotypic feature found in the study by Patel et al. (2016) [8]. The same study linked several genes, including GEMIN4, to cataracts using developmental lens expression and gene-network analysis [8]. A different study on prescreened multiplex consanguineous families described 33 novel candidate genes [29]. The study reported three unrelated families with three children harboring the same variant in GEMIN4. All three patients exhibited typical characteristics of the NEDMCR syndrome, and two of them showed stones and tubulopathy. In addition, they presented with severe dystonia and osteopenia. Maddirevula et al. (2018) [7] reported the same variant identified by Patel et al. (2016) and additional features that could suggest a phenotypic expansion of potentially distinct allelic disorders [8].

In summary, this report presents the full clinical features of two patients with a novel GEMIN4 pathogenic missense variant (c.440A>G; p.His147Arg) that causes NEDMCR syndrome. Our study provides a detailed comparison of the published cases and reports additional clinical features associated with the disease, such as hearing and speech impairment, dolichocephaly, scoliosis, and dysmorphism, and expands its phenotypic spectrum.

\section{List of the Databases}

https: / / www.ncbi.nlm.nih.gov/search/

http:/ / asia.ensembl.org/index.html

https://www.genecards.org/

http://genome.ucsc.edu/

https://gnomad.broadinstitute.org/

http://www.hgmd.cf.ac.uk/ac/index.php

https: / /www.lovd.nl/

https:/ / evs.gs.washington.edu/EVS/

http:/ / www.pantherdb.org 
Supplementary Materials: The following are available online at https:/ /www.mdpi.com/article/10 .3390/genes13010092/s1, Supplementary Table S1: Comprehensive in silico pathogenicity prediction analyses of the variant identified in this study, as well as previously identified variants for this disorder, using multiple prediction algorithms.

Author Contributions: Conceptualization, N.K.; methodology, S.T.A., D.C., A.A., K.O.A., A.A., H.A. (Hanan AlQudairy), S.A., N.A., M.A. and R.A.; software, S.T.A., D.C., A.A. and K.J.C.-L.; validation, A.A., S.T.A., D.C. and M.M.A.; formal analysis, A.A., S.T.A., D.C., N.K. and K.J.C.-L.; investigation, H.A. (Hesham Aldhalaan), K.O.A., A.A., H.A. (Hanan AlQudairy), S.A., N.A., M.A., R.A. and M.M.A.; resources, S.T.A., D.C. and K.J.C.-L.; writing-original draft preparation, H.A. (Hesham Aldhalaan), A.A., S.A., N.A., M.A., R.A., S.T.A., K.J.C.-L., D.C., K.O.A. and H.A. (Hanan AlQudairy); writingreview and editing, N.K., A.A., D.C., S.T.A., S.A., N.A., M.A., R.A. and M.M.A.; visualization, K.O.A., A.A., H.A. (Hesham Aldhalaan), S.A., N.A., M.A., R.A., S.T.A. and K.J.C.-L.; supervision, N.K., H.A. (Hesham Aldhalaan), S.T.A. and M.M.A.; project administration, N.K.; funding acquisition, N.K. All authors have read and agreed to the published version of the manuscript.

Funding: This research was funded by National Plan for Science, Technology, and Innovation program under King Abdulaziz City for Science and Technology (NSTIP/KACST), whom we wish to thank for their generous grant support to Namik Kaya, (Grant Number KACST\#14-MED2007-20).

Institutional Review Board Statement: The study was conducted according to the guidelines of the Declaration of Helsinki, and approved by the Institutional Review Board (or Ethics Committee) of King Faisal Specialist Hospital and Research Centre (KFSHRC, RAC\#2120022 on 23 August 2021, date of the approval).

Informed Consent Statement: Informed consents were obtained from all subjects participating in the study.

Data Availability Statement: Not applicable.

Acknowledgments: We are grateful to the participating patients and their families. We also extend our thanks to Genetics Core Laboratories, Research Advisory Council Committees, Saudi Genome Project team members, and KFSHRC Purchasing Departments for facilitating and expediting our requests. We thank National Plan for Science, Technology, and Innovation program under King Abdulaziz City for Science and Technology (NSTIP/KACST) for their generous grant support to Namik Kaya (KACST\#14-MED2007-20). We appreciate the continuous support and help that we received from KACST Biotech Team Members at KFSHRC.

Conflicts of Interest: The authors declare no conflict of interest.

\section{References}

1. Matera, A.G.; Wang, Z. A day in the life of the spliceosome. Nat. Rev. Mol. Cell Biol. 2014, 15, 108-121. [CrossRef]

2. Charroux, B.; Pellizzoni, L.; Perkinson, R.A.; Yong, J.; Shevchenko, A.; Mann, M.; Dreyfuss, G. Gemin4a novel component of the SMN complex that is found in both gems and nucleoli. J. Cell Biol. 2000, 148, 1177-1186. [CrossRef] [PubMed]

3. Lanfranco, M.; Cacciottolo, R.; Borg, R.M.; Vassallo, N.; Juge, F.; Bordonné, R.; Cauchi, R.J. Novel interactors of the Drosophila Survival Motor Neuron (SMN) Complex suggest its full conservation. FEBS Lett. 2017, 591, 3600-3614. [CrossRef] [PubMed]

4. Matera, A.G.; Raimer, A.C.; Schmidt, C.A.; Kelly, J.A.; Droby, G.N.; Baillat, D.; Have, S.T.; Lamond, A.I.; Wagner, E.J.; Gray, K.M. Composition of the Survival Motor Neuron (SMN) Complex in Drosophila melanogaster. G3 Genes | Genomes | Genet. 2019, 9, 491-503. [CrossRef]

5. Meier, I.D.; Walker, M.P.; Matera, A.G. Gemin4 is an essential gene in mice, and its overexpression in human cells causes relocalization of the SMN complex to the nucleoplasm. Biol. Open 2018, 7, 7. [CrossRef]

6. Mouillet, J.-F.; Yan, X.; Ou, Q.; Jin, L.; Muglia, L.J.; Crawford, P.A.; Sadovsky, Y. DEAD-Box Protein-103 (DP103, Ddx20) Is Essential for Early Embryonic Development and Modulates Ovarian Morphology and Function. Endocrinology 2008, 149, $2168-2175$. [CrossRef] [PubMed]

7. Maddirevula, S.; Alzahrani, F.; Al-Owain, M.; Al Muhaizea, M.A.; Kayyali, H.R.; AlHashem, A.; Rahbeeni, Z.; Al-Otaibi, M.; Alzaidan, H.I.; Balobaid, A.; et al. Autozygome and high throughput confirmation of disease genes candidacy. Genet. Med. 2018, 21, 736-742. [CrossRef]

8. Patel, N.; Anand, D.; Monies, D.; Maddirevula, S.; Khan, A.O.; Algoufi, T.; Alowain, M.; Faqeih, E.; Alshammari, M.; Qudair, A.; et al. Novel phenotypes and loci identified through clinical genomics approaches to pediatric cataract. Qual. Life Res. 2017, 136, 205-225. [CrossRef]

9. Sim, N.-L.; Kumar, P.; Hu, J.; Henikoff, S.; Schneider, G.; Ng, P.C. SIFT web server: Predicting effects of amino acid substitutions on proteins. Nucleic Acids Res. 2012, 40, W452-W457. [CrossRef] 
10. Adzhubei, I.A.; Schmidt, S.; Peshkin, L.; Ramensky, V.E.; Gerasimova, A.; Bork, P.; Kondrashov, A.S.; Sunyaev, S.R. A method and server for predicting damaging missense mutations. Nat. Methods 2010, 7, 248-249. [CrossRef]

11. Alirezaie, N.; Kernohan, K.D.; Hartley, T.; Majewski, J.; Hocking, T.D. ClinPred: Prediction Tool to Identify Disease-Relevant Nonsynonymous Single-Nucleotide Variants. Am. J. Hum. Genet. 2018, 103, 474-483. [CrossRef]

12. Shihab, H.A.; Gough, J.; Cooper, D.N.; Stenson, P.D.; Barker, G.; Edwards, K.J.; Day, I.N.M.; Gaunt, T.R. Predicting the Functional, Molecular, and Phenotypic Consequences of Amino Acid Substitutions using Hidden Markov Models. Hum. Mutat. 2012, 34, 57-65. [CrossRef] [PubMed]

13. Choi, Y.; Sims, G.E.; Murphy, S.; Miller, J.R.; Chan, A.P. Predicting the Functional Effect of Amino Acid Substitutions and Indels. PLoS ONE 2012, 7, e46688. [CrossRef] [PubMed]

14. Pagel, K.A.; Antaki, D.; Lian, A.; Mort, M.; Cooper, D.N.; Sebat, J.; Iakoucheva, L.M.; Mooney, S.D.; Radivojac, P. Pathogenicity and functional impact of non-frameshifting insertion/deletion variation in the human genome. PLoS Comput. Biol. 2019, 15, e1007112. [CrossRef]

15. Reva, B.; Antipin, Y.; Sander, C. Determinants of protein function revealed by combinatorial entropy optimization. Genome Biol. 2007, 8, R232. [CrossRef]

16. Rentzsch, P.; Witten, D.; Cooper, G.M.; Shendure, J.; Kircher, M. CADD: Predicting the deleteriousness of variants throughout the human genome. Nucleic Acids Res. 2019, 47, D886-D894. [CrossRef] [PubMed]

17. Schwarz, J.M.; Cooper, D.N.; Schuelke, M.; Seelow, D. MutationTaster2: Mutation prediction for the deep-sequencing age. Nat. Methods 2014, 11, 361-362. [CrossRef] [PubMed]

18. Schwarz, J.M.; Rödelsperger, C.; Schuelke, M.; Seelow, D. MutationTaster evaluates disease-causing potential of sequence alterations. Nat. Methods 2010, 7, 575-576. [CrossRef]

19. The UniProt Consortium. UniProt: A worldwide hub of protein knowledge. Nucleic Acids Res. 2019, 47, D506-D515. [CrossRef]

20. Ben Chorin, A.; Masrati, G.; Kessel, A.; Narunsky, A.; Sprinzak, J.; Lahav, S.; Ashkenazy, H.; Ben-Tal, N. ConSurf-DB: An accessible repository for the evolutionary conservation patterns of the majority of PDB proteins. Protein Sci. 2020, 29, 258-267. [CrossRef]

21. Buchan, D.W.A.; Jones, D.T. The PSIPRED Protein Analysis Workbench: 20 years on. Nucleic Acids Res. 2019, 47, W402-W407. [CrossRef]

22. Jones, D.T.; Cozzetto, D. DISOPRED3: Precise disordered region predictions with annotated protein-binding activity. Bioinformatics 2015, 31, 857-863. [CrossRef] [PubMed]

23. Shiwang, L.; Li, W.; Liu, S.; Xu, J. RaptorX-Property: A web server for protein structure property prediction. Nucleic Acids Res. 2016, 44, W430-W435. [CrossRef]

24. Mistry, J.; Chuguransky, S.; Williams, L.; Qureshi, M.; Salazar, G.A.; Sonnhammer, E.L.L.; Tosatto, S.C.E.; Paladin, L.; Raj, S.; Richardson, L.J.; et al. Pfam: The protein families database in 2021. Nucleic Acids Res. 2021, 49, D412-D419. [CrossRef] [PubMed]

25. Blum, M.; Chang, H.-Y.; Chuguransky, S.; Grego, T.; Kandasaamy, S.; Mitchell, A.; Nuka, G.; Paysan-Lafosse, T.; Qureshi, M.; Raj, S.; et al. The InterPro protein families and domains database: 20 years on. Nucleic Acids Res. 2021, 49, D344-D354. [CrossRef]

26. Hulo, N.; Bairoch, A.; Bulliard, V.; Cerutti, L.; De Castro, E.; Langendijk-Genevaux, P.S.; Pagni, M.; Sigrist, C.J. The PROSITE database. Nucleic Acids Res. 2006, 34, D227-D230. [CrossRef]

27. Jumper, J.; Evans, R.; Pritzel, A.; Green, T.; Figurnov, M.; Ronneberger, O.; Tunyasuvunakool, K.; Bates, R.; Žídek, A.; Potapenko, A.; et al. Highly accurate protein structure prediction with AlphaFold. Nat. Cell Biol. 2021, 596, 583-589. [CrossRef]

28. Rashed, M.S. Clinical applications of tandem mass spectrometry: Ten years of diagnosis and screening for inherited metabolic diseases. J. Chromatogr. B Biomed. Sci. Appl. 2001, 758, 27-48. [CrossRef]

29. Alazami, A.M.; Patel, N.; Shamseldin, H.E.; Anazi, S.; Al-Dosari, M.S.; Alzahrani, F.; Hijazi, H.; Alshammari, M.; Aldahmesh, M.A.; Salih, M.; et al. Accelerating Novel Candidate Gene Discovery in Neurogenetic Disorders via Whole-Exome Sequencing of Prescreened Multiplex Consanguineous Families. Cell Rep. 2015, 10, 148-161. [CrossRef]

30. Almuhaizea, M.; Almass, R.; Alhargan, A.; Albader, A.; Salsench, E.M.; Howaidi, J.; Ihinger, J.; Karachunski, P.; Begtrup, A.; Castell, M.S.; et al. Truncating mutations in YIF1B cause a progressive encephalopathy with various degrees of mixed movement disorder, microcephaly, and epilepsy. Acta Neuropathol. 2020, 139, 791-794. [CrossRef]

31. Chelban, V.; Alsagob, M.; Kloth, K.; Chirita-Emandi, A.; Vandrovcova, J.; Maroofian, R.; Davagnanam, I.; Bakhtiari, S.; AlSayed, M.D.; Rahbeeni, Z.; et al. Genetic and phenotypic characterization of NKX6-2 -related spastic ataxia and hypomyelination. Eur. J. Neurol. 2020, 27, 334-342. [CrossRef]

32. Sanderson, L.; Lanko, K.; Alsagob, M.; Almass, R.; Al-Ahmadi, N.; Najafi, M.; Al-Muhaizea, M.; Alzaidan, H.; AlDhalaan, H.; Perenthaler, E.; et al. Bi-allelic variants in HOPS complex subunit VPS41 cause cerebellar ataxia and abnormal membrane trafficking. Brain 2021, 144, 769-780. [CrossRef]

33. Al-Muhaizea, M.A.; Aldeeb, H.; Almass, R.; Jaber, H.; Binhumaid, F.; Alquait, L.; Abukhalid, M.; Aldhalaan, H.; Alsagob, M.; Al-Bakheet, A.; et al. Genetics of ataxia telangiectasia in a highly consanguineous population. Ann. Hum. Genet. 2021, 86, 34-44. [CrossRef]

34. Aldosary, M.; Baselm, S.; Abdulrahim, M.; Almass, R.; Alsagob, M.; AlMasseri, Z.; Huma, R.; AlQuait, L.; Al-Shidi, T.; AlObeid, E.; et al. SLC25A42 -associated mitochondrial encephalomyopathy: Report of additional founder cases and functional characterization of a novel deletion. JIMD Rep. 2021, 60, 75-87. [CrossRef] [PubMed] 
35. Mortensen, P.B.; Kølvraa, S.; Christensen, E.; Kplvraa, S. Inhibition of the Glycine Cleavage System: Hyperglycinemia and Hyperglycinuria Caused by Valproic Acid. Epilepsia 1980, 21, 563-569. [CrossRef] [PubMed]

36. Katayama, H.; Watanabe, M.; Yoshitomi, H.; Yoshida, H.; Kimoto, H.; Kamiya, A.; Hayashi, T.; Akimura, T. Urinary Metabolites of Valproic Acid in Epileptic Patients. Biol. Pharm. Bull. 1998, 21, 304-307. [CrossRef] [PubMed] 